\title{
A Review of Technical Requirements for High Penetration of Wind Power Systems
}

\author{
Yuan-Kang Wu1, Tung-Ching Lee', Ting-Yen Hsieh2, Wei-Min Lin² \\ ${ }^{1}$ Department of Electrical Engineering, National Chung-Cheng University, Chiayi, Taiwan \\ ${ }^{2}$ Green Energy and Environment Research Laboratories, Industrial Technology Research Institute, Hsinchu, \\ Taiwan \\ Email: allenwu@ccu.edu.tw, leedongjing@itri.org.tw, T.Y.Hsieh@itri.org.tw, wm.lin@itri.org.tw
}

Received October 2014

\begin{abstract}
Renewable portfolio targets have been established in many regions around the world. Regional targets such as $20 \%$ renewable energy by year 2020 are not uncommon. As the levels of wind power penetration increase, there are many power system impacts. This work investigated possible challenges and technical requirements for high penetration of wind power systems. The main issues to discuss covers reserve determination, wind power forecasting, unit commitment with appropriate generation portfolio, wind turbine and storage system technical development, demand response management, electricity market design, and frequency stability.
\end{abstract}

\section{Keywords}

Renewable, High Penetration, Wind Power

\section{Introduction}

The worldwide wind capacity reached 336,327 MW by the end of June 2014, out of which 17,613 MW were added in the first six months of 2014. This increase is a substantially higher than in the first half of 2013. All wind turbines installed worldwide by mid-2014 can generate around $4 \%$ of the world's electricity demand. Reasons for the relatively positive development of the worldwide wind markets certainly include the economic advantages of wind power and its increasing competitiveness relative to other sources of electricity. The fast fluctuation and unpredictable characteristics of wind velocity and random nature of failures of wind turbines make the generation output of wind farm stochastic and totally different from that of the conventional generating units. The incorporation of a large number of wind turbines into existing electric power systems can, therefore, bring complexities in system stability, reliability evaluation and power management.

A number of technical and economic challenges for high penetration of wind power systems. For example, the deployment of sufficient new transmission network capacity in the system planning timeframe [1]-[3], the development of advanced wind forecasting and power system scheduling tools for the system operational timeframe [4] [5], and the necessary re-evaluation of electricity market structures [6]-[8] are to name but a few. Most system balance studies for renewable integration in Hawaii have focused on expensive spinning reserves of fos- 
sil generation or electricity storage technologies to provide electricity when generation from renewable sources varies [9]. In ERCOT, the main challenges caused by wind power integration include the insufficient transmission capacity, wind power forecasting, and electricity market operation. In Ireland, the main problems are curtailment of wind energy production, transmission reinforce, grid code, increased fuel cost of traditional thermal generators, system inertia and frequency response, and reserve determination.

The disadvantages of incorporating high penetration wind power can be local (such as voltage dips, frequency variations and low power factors) and wide-scale (lower power system stability, lower reactive power/voltage control and power flow imbalances) [1] [10] [11]. In other words, electrical systems with high wind penetration levels would contain operational problems that reduce the economic value of wind energy and present a barrier to the unlimited development of wind energy. Therefore, several studies recommend that the existing standard protection relays on the distribution network, the ride through capability of thermal generators, the primary reserve requirements of thermal generators, the Grid Codes and operation standards all need to be reviewed to meet the higher penetration renewable target. The introduction of new technologies and strategies as forecasting, demand response management, novel technologies for storage systems and wind turbines, geographical dispersion, interconnections to neighbor systems and sophisticated power electronics would also mitigate the risk brought by high penetration of wind power systems. Furthermore, from many research reports, we can conclude that a scenario approach is essential for successful planning of an energy system, as well as planning of longterm energy demand that has to be met by the system.

\section{Challenge on High Wind Power Penetration}

\subsection{Increased Reserve Size}

The impact of wind on reserve requirements is a current area of interest for researchers and power system operators. Several rigorous methodologies and simulations are required to confirm that it is possible to reduce the deterministic reserve margins by using probabilistic methods and dynamic reserve allocation without compromising system reliability. Reserves may be classified by the direction of their actions. An upward response (up-regulation) is required when there is less generation than load. A downward response (down regulation) is required when there is more generation than load. Reserves can also be classified by their required response time. In other words, the reserve requirements should be time dependent and system specific, recognizing the system inertia and the operating characteristics of available units.

Reserves are required to maintain the short-term balance between power generation and load in an electricity system. In a system without renewable energies, imbalances between generation and load can be caused by contingency events or imperfect load predictions. The reserves are sized such that they ensure a pre-set reliability level for the whole power system. With the addition of renewable energies, the reserve sizes need to increase to maintain this level. Intermittent sources would affect reserve size, resulting from the uncertainty introduced by their imperfect power production forecast. For example, in Denmark and Germany, the regular primary and secondary/tertiary reserves have been used more frequently [10]. Moreover, a special hourly wind power reserve of $150 \mathrm{MW}$ with a 45-min deployment time has been instituted in one of the control areas in Germany [12]. The calculated reserve sizes differ among countries and regions because different reserve sizing methodologies that have been used. Several systems utilized Stat-B-VAR approach; some areas determined the required reserve based on historical measurements; some systems assume a wind variability of 2 MW per $100 \mathrm{MW}$ of installed capacity and a reserve size of $0.7 \%$ of peak load to balance load uncertainty, and several systems utilized dynamic reserve sizing based on the wind forecast error. Generally, the increase in reserve size becomes progressively larger at higher penetration levels. Some researches concluded that, for penetration rates up to 30\%, wind power will increase the size of the total primary reserves by $0.3 \%-1.0 \%$ of the installed wind capacity.

\subsection{Wind Power Forecasting Error}

It has been widely recognized that reliable wind forecasting tool is one of the most effect approaches toward optimal dispatching of wind power generations in a power system. The most important application of wind power forecasting is to reduce the need for balancing energy and reserve power, which results in the additional grid integration costs associated with wind integration. If the errors in wind power forecasting are reduced then electricity markets can trade with more certainty. Offshore wind farms pose more of a challenge in terms of accurate 
wind power forecasting and prediction. Therefore, it is evident that wind power forecasting has a major role to play in wind power optimization, to estimate the size and scale of system reinforcements and upgrades, the amount of balancing, reserves and storage.

The observed wind forecast error varies between countries. Day ahead RMSE forecast errors have been reported for Germany 4.5 - 6.5 [11] [12], Ireland (9.3\%) [11], and West Denmark (8.9\%) [10]. The day ahead RMSE forecast errors in US control areas ranged from 5\% to 15\% in 2009 [1]. Uncertainty in wind forecasts can lead to suboptimal unit commitment and dispatch [2], which affects the total operation cost. Therefore, a model that accounts for uncertainties in wind power production is recommended. Additionally, the need for more reliable wind power ramp events (ramp-ups \& ramp-downs) detection and prediction increases with high wind penetration levels. Accurate forecasting of ramp events are crucial to integrate large amounts of wind generation into the power grids and also to understand the risk involved at times of high variability.

\subsection{Unit Commitment with Increased Fuel Cost of Traditional Thermal Generators}

Traditional unit commitment strategies deploy generators according to their marginal cost and constraints related to ramping rates as well as minimum/maximum operation levels. There is little uncertainty in these models. Small variations in demand are handled through up/down regulation. Large loss of supply through the sudden unavailability of transmission or generation capacity is handled through $\mathrm{N}-1$ contingency planning. However, high integration of wind power drives conventional generators to an operational point of low efficiency.

With increasing wind power penetration, operation of thermal power plants will have to become more flexible to balance the variability in residual demand, and deal with the uncertainty of wind forecast errors. As a result, power plants will have to ramp up more often, run more part-load, and need to start up and shut down more often, which will all lead to increased fuel consumption. According to [13], additional cost increases by up to $8.3 \%$ at $20 \%$ penetration [13]. ESBNG estimated that increasing wind power penetration in the Republic of Ireland from $0 \%$ to $11.7 \%$ would result in an increase in total generation costs of Eur 196 million and that the largest change was in the operation of mid-merit order plant with 15 to 100 additional start-up's per year [14]. However, the actual increase should depend on the composition of the generation mix.

\subsection{Reduced Frequency Stability}

Increasing the amount of non-synchronous wind penetration will effectively displace traditional synchronous generation in the system dispatch. These non-synchronous generators are electrically decoupled from the grid and cannot provide direct inertial response as the grid frequency changes. It is known that a reduction in synchronous inertia would have significant frequency stability implications for smaller synchronous-island systems and its resultant generation/demand imbalance. System inertia is particularly important in smaller, more isolated power systems, with a relatively limited rotating inertia. According to the research in [15], a key finding is that frequency response and the dynamic stability are impacted at high instantaneous penetrations of wind power.

Recently, inertial emulation using turbine control functionality has been proposed as a possible mitigating factor. Currently, Ireland and Denmark have begun to implement wind inertia; National Grid UK has also outlined the future possibility for mandatory synthetic inertia control in wind farms. The large blades of wind turbines store kinetic energy and using a control mechanism, "synthetic" inertia from the wind turbines can be accessed. This is comparable to that of the conventional generator units.

\subsection{Design of Electricity Markets}

Integration of wind power into the competitive electricity market presents challenges to power system planners and operators. In competitive electricity markets, these generators are taken into the market differently than the dis-patchable generators. In some countries [16], wind generation is accommodated in day-ahead and hourahead energy markets without imbalance penalties. In some electricity market, wind generators are not allowed to bid and they are taken into the system when these powers are available. Normally, wind generators are paid at the actual energy market price plus a fixed premium [17]. Even at these prices, wind generators can only recover the cost if they get some subsidy from the governments. With the removal of subsidies from these generators, it would be very difficult for them to survive in the emerging electricity market unless a suitable market mechanism is devised to take care of their output powers. 
Most market operators plan for wind power uncertainties using wind forecasting tools, reserve plant and ancillary service agreements. Ancillary services are needed in order to support the transmission of power and maintaining reliable operation and ensuring the required level of power quality and safety. A set of ancillary services that the ISO can deliver to a competitive power market include types that support frequency stability (e.g., frequency control power, regulation and operating reserves), power balance (e.g., scheduling and dispatch of balancing energy), voltage control (e.g., tap changer control and reactive power control), restoration of supply (e.g., black start capability and island operation), or system management (e.g., power quality assurance. Several standards, such as IEEE standard 1547, have defined ancillary services, which are those provided by distributed resources interconnected to the electric power systems. However, if a high penetration of wind power is integrated into an electricity market, the market design would be more complicated, and the corresponding standards must be revised.

\subsection{Other Challenges}

High renewable penetration may also bring the challenge on different network types. These network types include DC link integration, commonly used when dc sources (PVs, fuel cells, and batteries) are integrated, AC link integration (turbines and rotating machines are integrated), and high-frequency ac link integration (fast response and decreased system size can be achieved). Also, various circuit topologies, such as regular networks, random networks, small-world networks, and scale-free networks, bring a more complex system

\section{Mitigation Measures to Reduce the Impact of High Wind Power Penetration}

There are many mitigation methods to reduce the risk of high penetration wind power system, such as demand response management (DSM), investments in smart grid technologies, technology to determine the operating reserve, curtailment of wind energy production or other power-limit methods, transmission reinforce, optimal generation portfolio, wind turbine and energy storage technology development, and calculation of capacity credit. The following sections will introduce the above-mentioned mitigation measures.

\subsection{Demand Response Management}

Demand response is an additional option by which the grid operator may ensure the balance of supply and demand by managing loads within and across hours. Demand response may represent a lower-cost, nearer-term solution for balancing variable supplies, and thus enable a country to achieve its goals of reducing fuel imports, reducing emissions, and promoting a greener local economy. There are many types of DSM measures. For example, in GB during 2005/6, load demands provided about one-third of the "standing reserve" and "frequency response" balancing service requirements of NGUK [y50]. Smart meters and time of use tariffs played important roles on the DSM measures; smart meters give electricity consumers access to information about the price of their electricity on a continuous basis. Time of use tariffs have been in existence for many years in the industrial, commercial, and domestic sectors. Tariffs aim to discourage use at peak demand times that normally coincide with peak prices. The most sophisticated development of time of use pricing responds continuously to changes in market prices. In some areas, such as Ireland, passive loads including electric water heating or electric space heating can become part of the demand response programs. Although currently electric space heating and electric water heating are expensive than gas or oil-fired heating, they could potentially provide the system operators with a large source of inexpensive DSM in high wind power systems [18]. Additionally, the Hawaiian Electric Company (HECO) has undertaken a demand response pilot project, with the primary goal of deferring investments in new generation capacity. The EnergyScout program used direct load control to curtail non-critical loads from commercial and residential customers, but only for emergency purposes [19].

Electric vehicles have also been suggested as the solution to the problems associated with excess wind electricity during a peak or off peak period. In the EU each Member State is mandated to ensure that $10 \%$ of transport energy comes from renewable sources by 2020 [20]. The Irish Government intends to achieve this target with a number of policies including ensuring that $10 \%$ of all vehicles in the transport fleet are powered by electricity by 2020 [21].

Pump Heat Electrical Storage (PHES) has been recognised as a technology that can integrate renewable energies either in planning or well advanced in terms of construction [22]. Scottish Southern Energy has advanced 
proposals for two PHES in Scotland, with an installed capacity of $300 \mathrm{MW}$ and $600 \mathrm{MW}$ each. There is also a highly conceptual PHES series of schemes, referred to as the "Spirit of Ireland" proposal, which supply $100 \%$ energy independence for Ireland using wind power and PHES.

However, according to the above-mentioned methods, the main challenges are the capital investment costs.

\subsection{Investments in Smart Grid Technologies}

Investments in smart grid technologies, such as battery electricity storage systems, advanced metering infrastructure (AMI), ICT equipment installation, and advanced power converters, have begun in several areas in order to limit the impact of power input from new wind and solar farms on grid stability. Additionally, the challenge of connecting a renewable source to the utility network can be largely solved by electronic power converters that handle two main tasks: maximum power transfer and power limit and active/reactive power control and power quality control. However, those systems are currently expensive.

\subsection{Technology to Determine the Operating Reserve}

The technology to determine the operating reserve is separated into deterministic and probabilistic methods. Both approaches may be either static or dynamic, whereby static methods assume the same reserve level regardless of system conditions, while dynamic reserve modifies the target level, often as a function of load and wind power.

\subsection{Curtailment of Wind Energy Production}

The larger the geographic area of installed wind power, the more steady and less intermittent the wind power generation because of the decreasing correlation in wind speeds at larger distances. Wind Energy curtailment can be caused by both insufficient transmission capacity and surplus wind power. When the total generation of essential capacity exceeds the residual load, wind power production is curtailed. Historical wind curtailment has been influenced by the availability of transmission and interconnection capacity. For example, insufficient transmission capacity in Germany caused curtailment: 0.2\% - 0.4\% in 2010 [3]. Also European countries with limited interconnections experienced more situation of surplus wind production: such as $1.2 \%$ in Italy, $0.5 \%$ in Spain, and 2.1\% in Ireland in 2012 [3]. In Ireland, there is a rule of thumb that wind power levels in excess of $50 \%$ are curtailed [23]; however, in 2012, a wind farm was put hold due to new curtailment rules in the All Island Grid (AIG) [24]. In the United States, the average curtailment level has been 5\% between 2008 and 2010 , primarily due to insufficient transmission capacity [4].

Wind power is curtailed mostly because it often generates power during hours of low load, whereas solar PV power production occurs during the middle of the day [5]. Therefore, combining these two renewable sources would reduce the overall curtailment.

In addition to wind power curtailment, other control methods for power fluctuations include:

- Ramp limit: the rate at which a wind farm increases or decreases its power output can be limited. In the event of rapidly falling wind speed, the ramp limit may be exceeded.

- Balance control: in the event of a rise in grid frequency, the wind farm reduces its output by a margin against the power output immediately prior to the grid frequency rise.

- Delta control: it is used in Denmark; in this mode an estimation of the available power is made and the wind farm output tracks at a fixed margin (or “delta”) below this.

- Maximum export limit: a wind farm would only output a fixed proportion of its rated capacity, in the event of the frequency dropping the wind farm would increase its output in proportion. This leads to a fixed output, variable margin approach. The available power is only used in the initial set-point calculation and to provide an update if it falls sufficiently far (5 MW for wind farms < $100 \mathrm{MW}$ or 5\% otherwise), that a given wind farm can't guarantee to provide the specified level of response.

\subsection{Transmission Reinforce}

When a large wind farm is integrated into the grid, the congestion problems are likely to happen in relatively short time periods characterized by high power injection from wind plants. Interconnection and the various proposals for a European super grid are seen as measures to mitigate the variability of wind power using geograph- 
ical dispersion. Europe's transmission system operators already have plans for improved interconnections, most of which are likely to benefit wind energy. For example, in UK, the energy regulator of gem provided for a major increase in electricity transmission systems investment plan over the 5-year period. This substantial increase reflects the need for investments in the electricity transmission systems infrastructure both aimed to accommodate the renewal and refurbishment of substantial portions of the UK's $400 \mathrm{kV}$ network and also accommodate the substantial growth in renewable generation. With respect to this, some 6 - $7 \mathrm{GW}$ of offshore generation is expected to connect to the transmission network.

\subsection{Optimal Generation Portfolio}

Limited flexibility of the generation portfolio can increase the amount of essential capacity, because more capacity is needed to supply reserves. As a result, the curtailment of the oversupply of wind power increases. In the future, if flexible natural gas and coal capacity can replace most of inflexible brown coal-fired generation, then the additional operation cost would be reduced.

Additionally, many wind power integration studies indicate that a diversified portfolio appears to have the least risk. Diversification can include additional thermal generation, increased renewable energies and energy storage and DSM, and increased market competition.

\subsection{Wind Turbine Technology Development}

In a typical power system, the grid frequency is controlled by the conventional power plants. However, with the increasing penetration of wind energy, it is expected than, in the near future, some grid-frequency support will be provided by the wind turbine itself. There are several researches related to the subject of frequency support using wind turbines. Most of the proposed methods use the kinetic energy stored in the wind-turbine rotating mass to provide additional power to the grid in case of frequency variation. Inertial "emulation" using turbine control functionality has been proposed as a possible mitigating factor to frequency stability challenge. The main target of inertial emulation is that wind generator can provide an inertial response to the power system similar to synchronous generators.

\subsection{Energy Storage Systems Development}

Many approaches have been proposed and carried out to address the issue of wind power fluctuations, among which energy storage systems (ESS) have attracted significant attention. The rated power and capacity are the most important parameters for energy storage facility planning as they directly influence the system's operation and profits. The ESS can be implemented using flywheels, super capacitors, lead-acid batteries, superconducting magnetic storage devices, and others.

\subsection{Calculation of Capacity Credit}

In traditional long term planning a number of reliability indices are used to plan the generation portfolio mix. These indices take into account random, partial and complete forced outages and the variations in load demand. However, when planning a power system with wind power, capacity credit is widely used to determine the amount of installed thermal plant that can be replaced by wind power.

\section{Conclusion}

There are many uncertainty issues surrounding interconnection as the ultimate solution to high levels of wind power. However, it is clear that portfolio diversification in terms of DSM, smart grid technologies, transmission reinforce, optimal generation portfolio, wind turbine and energy storage technology development, and calculation of capacity credit can reduce the operation risk in a high wind power penetration system. Therefore, these technologies should be further discussed.

\section{Acknowledgements}

The authors gratefully acknowledge the financial support by Ministry of Economic Affairs of Taiwan under Project: Grid interconnection policy and technical research for Renewable Energy (Project number: 103-D310). 


\section{References}

[1] Porter, K. and Rogers, J. (2010) Status of Centralized Wind Power Forecasting in North America. Report REL/ SR-550-47853. NREL, Colorado.

[2] Tuohy, A., Meibom, P., Denny, E. and O’Malley, M. (2009) Unitcommitment for Systems with Significant Wind Penetration. IEEE Transactions on Power Systems, 24, 592-601. http://dx.doi.org/10.1109/TPWRS.2009.2016470

[3] Lew, D., Bird, L., Milligan, M., Speer, B., Wang, X. and Carlini, E.M. (2013) Wind and Solar Curtailment-Preprint. Report NREL/CP-5500-60245. NREL, Colorado.

[4] Porter, K., Rogers, J. and Wiser, R. (2011) Update on Wind Curtailment in Europe and North America.

[5] Bertsch, J., Growitsch, C., Lorenczik, S. and Nagl, S. (2012) Flexibility Options in European Electricity Markets in High RES-Escenarios-Study on Behalf of the International Energy Agency. Energiewirtschaftliches Institutan Der Universität ZuKöln (EWI), Germany.

[6] Gross, R., Heptonstall, P., Anderson, D., Green, T., Leach, M. and Skea, J. (2006) The Costs and Impacts of Intermittency. London UKERC.

[7] Ding, Y., Singh, C., Goel, L. and Wang, P. (2014) Short-Term and Medium-Term Reliability Evaluation for Power Systems With High Penetration of Wind Power. IEEE Transactions on Sustainable Energy, 5, 896-906. http://dx.doi.org/10.1109/TSTE.2014.2313017

[8] Karki, R., Thapa, S. and Billinton, R. (2012) A Simplified Risk-Based Method for Short-Term Wind Power Commitment. IEEE Transactions on Sustainable Energy, 3, 498-505. http://dx.doi.org/10.1109/TSTE.2012.2190999

[9] Critz, D.K., Busche, S. and Connors, S. (2013) Power Systems Balancing with High Penetration Renewables: The Potential of Demand Response in Hawaii. Energy Conversion and Management, 76, 609-619. http://dx.doi.org/10.1016/j.enconman.2013.07.056

[10] Holtinen, H., Meibom, P., Orths, A., Van Hulle, F., Lange, B. and Malley, M.O. (2009) IEA Wind Task 25 Design and Operation of Power Systems with Large Amounts of Wind Power. Final Report, Phase One 2006-08. VVT Technical Research Centre, Helsinki.

[11] Giebel, G. (2011) SafeWind Deliverable D1.2: The State of the Art in Short-Term Prediction of Wind Power. Risoe DTU. Wind Energy Division, Roskilde.

[12] Ernst, B., Schreier, U., Berster, F., Scholz, C., Erbring, H. and Schlunke, S. (2010) Large-Scale Wind and Solar Integration in Germany. Report PNNL-19225. Pacific Northwest National Laboratory, Richland.

[13] Gonzalez-Longatt, F., Chikuni, E. and Rashayi, E. (2013) Effects of the Synthetic Inertia from Wind Power on the Total System Inertia after a Frequency Disturbance. IEEE International Conference on Industrial Technology, 826-832.

[14] ESB National Grid, Impact of Wind Power Generation in Ireland on the Operation of Conventional Plant and the Economic Implications, 2004.

[15] Miller, N.W., Shao, M., Venkataraman, S., Loutan, C. and Rothleder, M. (2012) Frequency Response of California and WECC under High Wind and Solar Conditions. IEEE Power and Energy Society General Meeting.

[16] Piwko, R., Osborn, D., Gramlich, R., Jordan, G., Hawkins, D. and Porter, K. (2005) Wind Energy Delivery Issues. IEEE Power \& Energy Magazine, 3, 47-56. http://dx.doi.org/10.1109/MPAE.2005.1524620

[17] Fabbri, A., Roman, T.G.S. Abbad, J.R. and Quezada, V.H.M. (2005) Assessment of the Cost Associated with Wind Generation Prediction Errors in a Liberalized Electricity Market. IEEE Transactions on Power Systems, 20, 1440-1446. http://dx.doi.org/10.1109/TPWRS.2005.852148

[18] Elkraft System, Long-Term Challenges in the Electricity System. 2005.

[19] Hawaiian Electric Company. Demand-Side Management Programs: Accomplishments and Surcharge Report. Public Utilities Commission of the State of Hawaii, Honolulu, 2010.

[20] Official Journal of the European Union, Directive 2009/28/EC of the European Parliament and of the Council of 23 April 2009 on the Promotion of the Use of Energy from Renewable Sources.

[21] Gormley, J. (2008) Minister for Environment, Heritage and Local Government. Ireland Press Release.

[22] Deane, J.P., Ó Gallachóir, B.P. and McKeogh, E.J. (2010) Techno-Economic Review of Existing and New Pumped Hydro Energy Storage Plant. Renewable and Sustainable Energy Reviews, 14, 1293-1302.

http://dx.doi.org/10.1016/j.rser.2009.11.015

[23] Byrne, D. (2010) Science foundation Ireland. Ireland-Taiwan Work shop on ICT and Energy. Keynote Address.

[24] O’Halloran, B. (2012) Wind Energy Limit See sESB Put h40m Project on Hold. The Irish Times. http://www.irishtimes.com/newspaper/finance/2012/0227/1224312437178.html 